\title{
Investigation of the Release of Particles from a Nanocoated Product
}

\author{
Olivier Le Bihan ${ }^{1 *}$, Neeraj Shandilya ${ }^{1,2}$, Ludovic Gheerardyn², Olivier Guillon ${ }^{3}$, \\ Emanuel Dore ${ }^{2}$, Martin Morgeneyer ${ }^{2}$ \\ ${ }^{1}$ Institut National de l'Environnement industriel et des RISques (INERIS), Verneuil-en-Halatte, France \\ ${ }^{2}$ Université de Technologie de Compiègne (UTC), Compiègne, France \\ ${ }^{3}$ Renault, Guyancourt, France \\ Email: "olivier.le-bihan@ineris.fr
}

Received December 24, 2012; revised January 22, 2013; accepted January 30, 2013

\begin{abstract}
Manufactured products are being coated with nanoparticles in order to functionalize them with antibacterial or self-cleaning properties or to improve their durability etc. As the (eco-)toxicological effects of the nanoparticles are not well known yet, their use could lead to new potential risks for the workers, the consumers and the environment. This study focuses on the release of the nanoparticles during the operations related to the handling and processing of an automotive part. The part is made up of a metallic alloy and, in order to reduce friction, the part is nano-coated with inorganic fullerenes. The mechanical stresses appearing during these operations are reproduced in a nano-secured facility. The release of nanoparticles is found to be increasing with the wear energy applied on the surface.
\end{abstract}

Keywords: Nanoparticle; Coating; Emission; Wear; Friction; Release

\section{Introduction}

There is a growing interest in the development of nanocoatings in industrial applications. The finished products, once nano-coated, can be self-cleaning, antibacterial, UV-resistant etc. Due to these advantages, their usage is becoming frequent and thus, subjected to investigations regarding the release of nanoparticles (NP) in the air, which may pose toxicological effects on the human and the environment. These effects of NPs are not well known yet and represent thus a possible threat, especially, since a new era of this new technology is commencing hastily. During their whole life-cycle, the products are exposed to wear by their environment and utilization and thus degradation might occur, [1-3] which could lead to the release of NP. However, in view of the large variety of possible exposures, the present data are still not sufficient. Moreover, as workplace atmosphere inspection for manufactured nanoparticles is relatively complex and expensive to conduct, new comprehensive studies may be required to provide estimates of their release in the occupational exposure. The need for these studies will rapidly increase due to growing production and use of manufactured nanoparticles. Previous studies (Table 1) have shown the emission of particles from different types of materials when solicitated mechanically or thermomechanically or by UV. For environmental degradation,

\footnotetext{
"Corresponding author.
}

it has been shown that exposure to UV radiations can lead to the increase of the density of NPs on the surface of a nano-structured polymer composite [3]. Fewer works have studied the exposure risks during handling and operating nanoparticles [4]. But new heights have been achieved when the nanoparticles were started being characterized during their generation process through wear. Their characterization also got encouraged with the fact that in several cases of mechanical wear, very high particle emissions have been observed for nanostructured materials, e.g. when drilling, [5] grinding, [6] or sanding [7] (see Table 1). From comparisons of materials with and without nano-structure, it has been confirmed that emission of particles occurs in both cases $[5,7]$. The study presented here aims at characterizing a possible source of NP release to air, which may lead to their inhalation and thus the possible worker exposure to NP during the operations related to the handling and processing of an automotive nanocoated part. Analysis has been carried out to quantify and characterize the particle emission levels of the part during the subsequent wear processes. An attempt, simulating these wear processes in real life conditions experimentally, is presented.

\section{Experiments}

For the experimental investigation, an iron alloy shaft cap with a radius of $2 \mathrm{~cm}$ and height $5 \mathrm{~cm}$ was used. Its 
Table 1. Overview of references.

\begin{tabular}{|c|c|c|c|c|}
\hline \multirow[b]{2}{*}{ Material } & \multirow[b]{2}{*}{ Wear mechanism } & \multicolumn{2}{|r|}{ Particle emission } & \multirow[b]{2}{*}{$\begin{array}{l}\text { Reference } \\
\text { number }\end{array}$} \\
\hline & & $\begin{array}{l}\text { Total number } \\
\text { concentration } \\
\text { and size range }\end{array}$ & Main observations and findings & \\
\hline $\begin{array}{l}\text { Coated surfaces with } \\
\text { zinc oxide nanoparticles }\end{array}$ & $\begin{array}{c}\text { Abrasion with a } \\
\text { Taber }\end{array}$ & $\begin{array}{c}<20 \text { particles } / \mathrm{cm}^{3} \\
{[6 \mathrm{~nm}-1 \mu \mathrm{m}]}\end{array}$ & $\begin{array}{l}\text { The total number of generated submicrometer or } \\
\text { nanoparticles was extremely low and lay below the statistic } \\
\text { significance threshold. The particles }<100 \mathrm{~nm} \text { remain } \\
\text { embedded in the coarse wear particles. }\end{array}$ & {$[10]$} \\
\hline $\begin{array}{c}\text { Polycarbonate } \\
\text { containing } 3 \% \mathrm{wt} \\
\text { Carbon Nanotube }(\mathrm{CNT})\end{array}$ & $\begin{array}{c}\text { Abrasion with a } \\
\text { Taber }\end{array}$ & $\begin{array}{c}50-1800 \\
\text { particles } / \mathrm{cm}^{3} \\
{[7 \mathrm{~nm}-10 \mu \mathrm{m}]}\end{array}$ & $\begin{array}{l}\text { The abrasion effect is enhanced when increasing the normal } \\
\text { force. The particle emission is also increased with the speed } \\
\text { (number of cycle per minute). No free CNTs were observed. }\end{array}$ & [8] \\
\hline $\begin{array}{l}\text { Polymethyl } \\
\text { Methacrylate (PMMA) } \\
\text { containing } 10 \% \text { wt Cu }\end{array}$ & $\begin{array}{c}\text { Abrasion with a } \\
\text { Taber }\end{array}$ & $\begin{array}{l}\text { Up-to } 10,000 \\
\text { particles } / \mathrm{cm}^{3} \\
{[7 \mathrm{~nm}-10 \mu \mathrm{m}]}\end{array}$ & $\begin{array}{l}\text { The type of abrasion tool has a high impact on particle } \\
\text { emission intensity. No visible free } \mathrm{Cu} \text { nanoparticles were } \\
\text { observed even for one case they would be nearly released. }\end{array}$ & [9] \\
\hline $\begin{array}{c}\mathrm{TiO}_{2} \text { nanopowder } \\
\text { coated on different } \\
\text { substrates including } \\
\text { wood, polymer and tile. }\end{array}$ & $\begin{array}{c}\mathrm{UV}+\text { fan }+ \text { rubber } \\
\text { knife }\end{array}$ & $\begin{array}{l}\sim 10 \text { to } 600 \\
\text { particles } / \mathrm{cm}^{3} \\
{[15-661 \mathrm{~nm}]}\end{array}$ & $\begin{array}{l}\text { These actions together can greatly reduce the binding force } \\
\text { between the } \mathrm{TiO}_{2} \text { nanopowder and the substrate surface, } \\
\text { and, therefore produce particle emissions from the coating } \\
\text { products. }\end{array}$ & {$[15]$} \\
\hline $\begin{array}{l}\text { Paints with or without } \\
\text { engineered nanoparticles } \\
(\mathrm{NP}) . \mathrm{NP} \text { : carbon black } \\
\text { and } \mathrm{TiO}_{2}\end{array}$ & Sanding & $\begin{array}{l}14,000-28,000 \\
\text { particles } / \mathrm{cm}^{3} \\
{[5 \mathrm{~nm}-20 \mu \mathrm{m}]}\end{array}$ & $\begin{array}{l}\text { The sander was the only source of particles smaller than } 50 \\
\mathrm{~nm} \text { and they dominated the number concentration spectra. } \\
\text { NPs released during the sanding do not occur in individual } \\
\text { particles. }\end{array}$ & {$[7]$} \\
\hline $\begin{array}{l}\text { Non-nanodoted } \\
\text { materials: Granite, } \\
\text { Ceramic, Steel, } \\
\text { Aluminum, PTFE, } \\
\text { Hardwood }\end{array}$ & Grinding & $\begin{array}{l}10,000-800,000 \\
\text { particles } / \mathrm{cm}^{3} \\
{[4 \mathrm{~nm}-20 \mu \mathrm{m}]}\end{array}$ & $\begin{array}{l}\text { Ultrafine particles do have the potential to form a significant } \\
\text { component of a grinding aerosol for a number of substrates. } \\
\text { processes: 1) from within the grinding motor, 2) from the } \\
\text { combustion of amenable grinding substrates and 3) from } \\
\text { volatilization of amenable grinding materials at the grinding } \\
\text { wheel/substrate interface. }\end{array}$ & {$[6]$} \\
\hline $\begin{array}{l}\text { Surfboard with or } \\
\text { without carbon } \\
\text { nanotubes }(\mathrm{CNT})\end{array}$ & $\begin{array}{l}\text { Drilling and } \\
\text { grinding }\end{array}$ & $\begin{array}{l}\text { Upto } 107 \\
\text { particles } / \mathrm{cm}^{3} \\
{[7 \mathrm{~nm}-10 \mu \mathrm{m}]}\end{array}$ & $\begin{array}{l}\text { When used, the CNT are not placed in the outside layer, but } \\
\text { inside. Material with or without CNT: the particle emissions } \\
\text { are comparable. The top layer (varnish) is the major source } \\
\text { of particles. }\end{array}$ & {$[5]$} \\
\hline $\begin{array}{l}\text { Steel and fiber cement } \\
\text { panels coated with the } \\
\mathrm{ZnO} \text { and } \mathrm{Fe}_{2} \mathrm{O}_{3} \\
\text { nanoparticles }\end{array}$ & Sanding & $\begin{array}{c}\text { Upto } 109 \\
\text { particles } / \mathrm{cm}^{3}\end{array}$ & $\begin{array}{l}\text { For the given stress, the swarf mass, the particle size } \\
\text { distribution of the released aerosol, and consequently the } \\
\text { number of released particles depend primarily on the used } \\
\text { surface coating. }\end{array}$ & {$[11]$} \\
\hline $\begin{array}{l}\text { Epoxy nanocomposites } \\
\text { reinforced with CNTs }\end{array}$ & $\begin{array}{l}\text { Weighing } \\
\text { operation and } \\
\text { sanding }\end{array}$ & $\begin{array}{l}\text { With no local } \\
\quad \text { exhaust } \\
\text { ventilation: } 2.68 \\
\mu \mathrm{g} / \mathrm{m}^{3} \text { Inside the } \\
\text { fume hood: } 21.4 \\
\qquad \mu \mathrm{g} / \mathrm{m}^{3}\end{array}$ & $\begin{array}{l}\text { This study demonstrated that weighing bulk CNTs and } \\
\text { sanding epoxy containing CNTs generate few airborne } \\
\text { particles that are nano-sized. Furthermore, it was } \\
\text { demonstrated that sanding epoxy containing CNTs may } \\
\text { generate micrometer-sized particles with CNTs protruding } \\
\text { from the main particle core. }\end{array}$ & {$[12]$} \\
\hline PA6 nanocomposites & Drilling & $\begin{array}{c}20,000 \\
\text { particles } / \mathrm{cm}^{3} \\
{[175 \text { and } 350 \mathrm{~nm}]}\end{array}$ & $\begin{array}{l}\text { It is likely that the presence of nanoclay in some way retains } \\
\text { the formation of high quantity of airborne particles and } \\
\text { promotes particle deposition. }\end{array}$ & [13] \\
\hline Concrete & Cutting & $\begin{array}{c}5.28 \pm 1.26 \\
\mathrm{mg} / \mathrm{m}^{3}\end{array}$ & $\begin{array}{l}\text { An increase in CS resulted in an increase in the four } \\
\text { measured particle exposure levels resulting from its } \\
\text { influence on the generation of coarse particles. For both } \\
\text { Ctho and Cres which are known to have a higher content of } \\
\text { fine particles, the increase in AF resulted in an increase in } \\
\text { their concentrations. However, for the concentrations with a } \\
\text { higher fractions of coarse particles (i.e., Ctot and Cinh), the } \\
\text { increase in AF led to an initial increase, followed by a } \\
\text { decrease in measured particle exposure concentrations. }\end{array}$ & {$[14]$} \\
\hline
\end{tabular}

surface was coated homogeneously with inorganic fullerene, having a coating thickness of $0.1 \mu \mathrm{m}$. The coating ensures the lowering of its friction coefficient. An emission chamber i.e. a sealed glove box (model 830-ABC/EXP, Plas-Labs), has been used to ensure lim- ited background particles concentration inside the chamber and to prevent the release of (nano) particles to the outside atmosphere, thus, providing a nano-secured facility. The details of all the instruments, used during the test, are given in Table 2. During the whole test, clean air 
Table 2. Instrumentation.

\begin{tabular}{ccccc}
\hline Parameter & Technique & Instruments & Characteristics & Set sample time \\
\hline Number concentration & Condensation & TSI model 3785 & Water-based & $1 \mathrm{~s}$ \\
{$[4 \mathrm{~nm}-1 \mu \mathrm{m}]$} & Particle Counter (CPC) & Grimm model 5.400 & Butanol-based & $6 \mathrm{~s}$ \\
Size distribution & Scanning Mobility Particle & DMA TSI model 3081+ & & $235 \mathrm{~s}$ \\
{$[10 \mathrm{~nm}-0.5 \mu \mathrm{m}]$} & Sizer (SMPS) & CPC TSI model 3010 & & $6 \mathrm{~s}$ \\
Size distribution & Optical Counter (COP) & Grimm model 1.108 & & \\
{$[0.3-20 \mu \mathrm{m}]$} & &
\end{tabular}

(Filtered Air Supply 3074B, TSI) is passed upwards through the chamber. All devices are fed from a unique sampling point, which is set above the testing part to collect the maximum of particles released into the air from the experiment (Figure 1). The clean air inlet flow rate is equal to $0.075 \mathrm{lps}$. It enhances to carry out the investigation in an atmosphere practically free of particles $\left(2\right.$ particles $\left./ \mathrm{cm}^{3}\right)$ and thus to detect emitted particles even at the low emission levels. Two Condensation Particle Counters-water based CPC (model 3785, TSI) and a butanol-based CPC (model 5.400, Grimm) - have been used in parallel which enabled reliable measurements of even low particle number concentrations, in the range of particle sizes from $4 \mathrm{~nm}$ to $1 \mu \mathrm{m}$. The particle size distribution is measured by a Scanning Mobility Particle Sizer (SMPS) configured with a long Differential Mobility Analyzer (DMA, model 3081) for particles' size ranging from $10 \mathrm{~nm}$ to $500 \mathrm{~nm}$ and by an Optical Particle Counter (OPC, model 1.108, Grimm) for particles' size ranging from $300 \mathrm{~nm}$ to $20 \mu \mathrm{m}$. The total sample time for SMPS has been kept at $235 \mathrm{~s}$ (scan time $215 \mathrm{~s}$, retrace time $20 \mathrm{~s}$ ) whereas for other instruments, it has been kept at low values. For validating the scan by SMPS, it was operated only under stable particle concentration conditions. However, a rougher state of the particles concentration stability cannot be neglected and excluded from the scanning period in these types of experiments. The experimental investigations presented here are corresponding to the operations which occur when a part, under development, is handled e.g. for unpacking, roughness measurement, specimen preparation for microscopy observations and other tests. In order to simulate these real life operations at real scale, following experiments have been carried out sequentially on a given part with increasing levels of stresses: 1) Extraction from the safety bag; 2) Plastic bag agitation; 3) Part extraction from plastic bag; 4) Part moves in 3 dimensions; 5) Surface rubbing with glove; 6) Falling from a height of 20 $\mathrm{cm}$; 7) Surface scratching in 3 directions; 8) Surface sawing; 9) Surface sanding. The sampling point to measure the particles number concentration has been kept in the vicinity of the source. All the above mentioned operations were carried out in a glove box measuring 300 $\mathrm{cm} \times 240 \mathrm{~cm} \times 360 \mathrm{~cm}$. For test $\# 9$, the rotary tool's motor (Dremel 400 DIGITAL with a rotating aluminum oxide abrasive wheel) has been placed outside the chamber to avoid the contamination from the particles released by the motor's brushes. Its velocity of rotation has been kept at $19,000 \mathrm{rpm}$. It is interesting to note that these activities are also arranged in ascending order of wear energy levels. The wear energy associated with a system in a process can be defined as the energy consumed during machining or erosion or deterioration of the system during that process. The precautions for nanosafety are achieved by placing the glove-box within a nanosecured venting hood and putting the sample parts into two plastic bags, when not in use. However, due to the lack of the information on homogenization of the inside air due to ventilation, inlet and exhaust valves, and data available on the measure of the particles number concentration should be considered as semi-quantitative. In order to ensure the repeatability of data and results presented in the present work, the whole experimental procedure was repeated three times. The particle deposition on the surface walls is a critical issue in such experiments which are done in a confined area. This may lead to the carrying out of these particles from one experimental trial to another. An utmost care has been taken to avoid it by cleaning the surface walls using an ethanol absorbed paper after every test and trial.

\section{Experimental Results}

The number concentration of the released particles versus time, measured by means of COP Grimm, water based CPC and butanol based CPC, in a sequential order, is shown in Figure 2. Note that Figure 2 depicts the number concentration during one of the three trials. The particle concentration level appearing before applying any stress (often referred as background noise level) is approximately 2 particles $/ \mathrm{cm}^{3}$. During test \#1, i.e. extraction of the part from its bag, a particle concentration of 4 particles $/ \mathrm{cm}^{3}$ was measured. Tests $\# 2$ to $\# 7$ generate peaks of particle concentration of approximately 10 particles $/ \mathrm{cm}^{3}$, while peaks for sawing (test \#8) range from 50 to 1000 particles $/ \mathrm{cm}^{3}$. Test \#9 generates highest concentration level of 900 particles $/ \mathrm{cm}^{3}$ which is measured for the particles lying in a size range of $10 \mathrm{~nm}$ to $0.5 \mu \mathrm{m}$, as shown in Figure 3. From Figure 3, it is evident that 


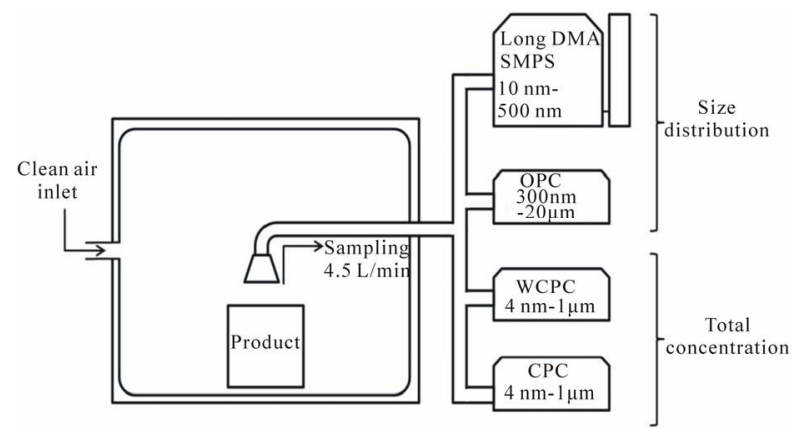

Figure 1. Experimental set-up.

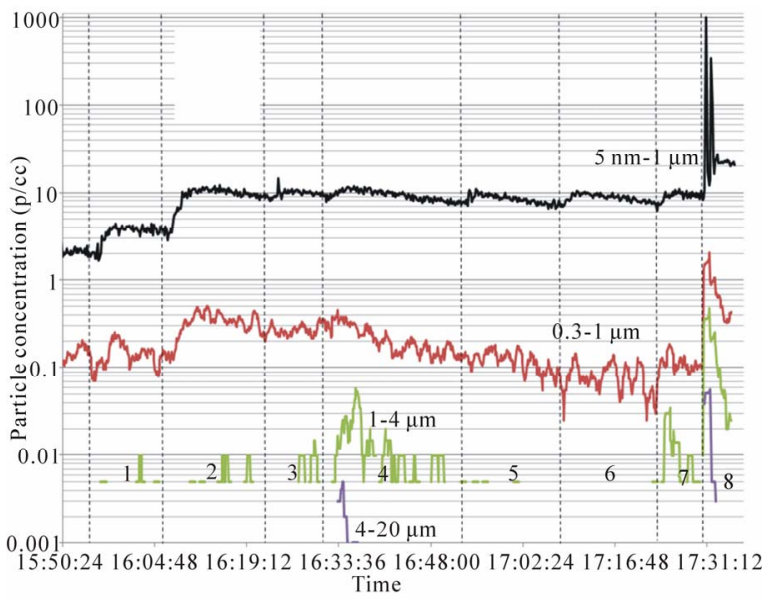

Figure 2. Particle concentration through time for different size ranges while testing a single nanocoated part (cf. Table 3 , except sanding).

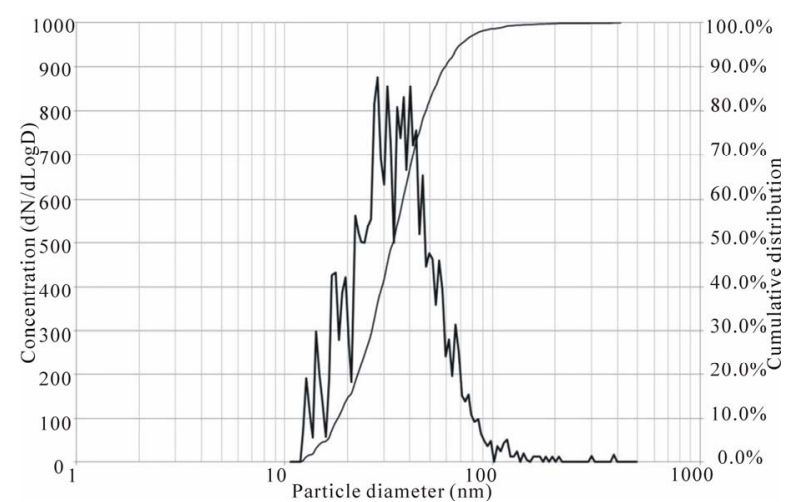

Figure 3. Particle size distribution while sanding measured by SMPS.

$50 \%$ of the particles generated during sanding are smaller than $40 \mathrm{~nm}$.

During tests \#1 to \#5, the wear energy levels are very low due to low level of stress application. For the particles lying in the size range of $5 \mathrm{~nm}$ to $1 \mu \mathrm{m}$, their concentrations were found to be in the range of 4 to 12 parti$\mathrm{cles} / \mathrm{cm}^{3}$. For micron sized particles, concentration levels are also low. Therefore, from these observations, it has been found that for the present nanocoated shaft cap, handling operations (tests \#1 to \#5) do not involve any particle emission or their exposure threats to the operator. However, for the tests $\# 6$ to $\# 9$, there may be possibility of a considerable particle emission because of the involvement of high levels of stress application. However, for tests \#6 and \#7, this hasn't been seen so far. The only phase where a significant emission has been seen is test \#9. In this test, as soon as the sanding commences, there occurs a sharp peak of the number concentration due to the ejection of the particles from the material. To have a stable particle concentration during the particles size scanning by SMPS, the scan starts after the peak has arrived and it starts diminishing slowly with time, thus, providing a rough but stable particles presence.

\section{The Energetic Approach}

In the present approach, we have seen a series of operations involving increasing order of stresses acting on the nano-coated part. For the handling operations involving low stresses (\#1 to \#5), the particles emission is negligible. For the test \#6, which involves accidental fall of the part, the same low emission continues. In order to get a better insight of this accidental scenario, the type of material in play should be noted. This is a light weight iron alloy which has got a high value of impact strength and ductility. The impact stress to which it is subjected at the end of the fall was calculated and found to be less than $100 \mathrm{~Pa}$ Equation (1) which is very less in magnitude as compared to its material impact strength. This means, all the impact applied on this nano-coated part gets sufficiently absorbed by rendering the part untouched. As a result, the wear energy applied on this part seemed to be lesser than required in order to have a higher particles emission. But if the same wear energy had been applied on a brittle material having very low impact strength (ex. Ceramics, concrete, glass etc.) the scenario of accidental fall would have produced high particles emission concentration. Therefore, it shows that the particles emission depends on both the wear energy level as well as the material to which it is being applied. For test \#7, the low particle emission concentration during the peeling off of nanocoating signifies the sustainability of integrity of nanocoating during getting peeled off. However, it still requires a better view on structural changes occurring during this process. In Table 4, the values of wear energy are shown with their corresponding total particle number concentrations. For the calculation, following basic equations have been employed:

For accidental fall:

$$
E_{a}=m * g * h
$$

For scratching and sawing:

$$
E_{d}=\mu * F_{N} * d
$$


Table 3. Stress tests-description, aim and results.

\begin{tabular}{|c|c|c|c|c|c|c|c|}
\hline \multirow{2}{*}{ \# } & \multirow{2}{*}{ Description } & \multirow{2}{*}{ Aim } & \multirow{2}{*}{ Wear Energy level } & \multicolumn{4}{|c|}{ Total Particle emission concentration $\left(\# / \mathrm{cm}^{3}\right)$} \\
\hline & & & & $5 \mathrm{~nm}-1 \mu \mathrm{m}$ & $0.3-1 \mu \mathrm{m}$ & $1-4 \mu \mathrm{m}$ & $4-20 \mu \mathrm{m}$ \\
\hline 1 & $\begin{array}{l}\text { Extraction from the } \\
\text { safety bag }\end{array}$ & & Very low & 2 & $\sim 0$ & $\sim 0$ & $\sim 0$ \\
\hline 2 & Plastic bag agitation & Nanoparticles release while & Very low & 10 & $<1$ & $\sim 0$ & $\sim 0$ \\
\hline 3 & $\begin{array}{l}\text { Part extraction } \\
\text { from plastic bag }\end{array}$ & handling the part & Very low & 10 & $\sim 0$ & $\sim 0$ & $\sim 0$ \\
\hline 4 & $\begin{array}{c}\text { Part moves in } \\
3 \text { dimensions }+ \text { shock test }\end{array}$ & & Very low & 10 & $\sim 0$ & 10 & + \\
\hline 5 & Surface rubbing with glove & Accidental scenario \#1 & Very low & 10 & $\sim 0$ & $\sim 0$ & $\sim 0$ \\
\hline 6 & $\begin{array}{l}\text { Falling from a } \\
\text { height of } 20 \mathrm{~cm}(\mathrm{~h})\end{array}$ & Accidental scenario \#2 & Low & 10 & $\sim 0$ & $\sim 0$ & $\sim 0$ \\
\hline 7 & $\begin{array}{l}\text { Surface scratching } \\
\text { (3 directions) }\end{array}$ & $\begin{array}{c}\text { Nanoparticles release } \\
\text { during roughness measurement }\end{array}$ & Low & 12 & $<1$ & $\sim 0$ & $\sim 0$ \\
\hline 8 & Surface sawing & $\begin{array}{c}\text { Nanoparticles } \\
\text { releaseduring sample } \\
\text { preparation for microscopy }\end{array}$ & Medium & 300 & 2 & $<1$ & $<1$ \\
\hline 9 & Surface sanding & Extreme stress & High & 100,000 & $\mathrm{X}$ & $\mathrm{X}$ & $\mathrm{X}$ \\
\hline
\end{tabular}

For sanding:

$$
E_{d}=\mu * F_{N} * r * \omega * t
$$

with $E_{a}$ is the energy absorbed $(\mathrm{J}), \mathrm{m}$ is the mass $(\mathrm{kg}), g$ is the acceleration due to gravity $\left(\mathrm{m} / \mathrm{s}^{2}\right), h$ is the height of the fall, $E_{d}$ is the energy loss $(\mathrm{J}), F_{N}$ is the normal load $(\mathrm{N}), d$ is the crossed distance $(\mathrm{m}), \mu$ is the friction coefficient, $r$ is the radius of the abrasive wheel $(\mathrm{m}), \omega$ is the velocity of rotation ( $\mathrm{rad} / \mathrm{s})$ and $t$ is the stress duration ( $\mathrm{s}$ ). In Figure 4, the wear energy levels applied on the nanocoated part have been plotted on a log-log graph. The four points in the Figure 4 correspond to the four energy levels in the tests \#6 to \#9. Clearly, with increasing wear energy level, particles emission concentration also increases, hence a direct proportionality between the two.

\section{Discussions and Conclusions}

The study presented here investigates the release of nanoparticles during the operations related to the handling of and processing of a nano-coated shaft cap. For different types of wear, concentration levels of emitted particles in air have been measured. The whole experimental procedure was divided in nine carefully selected tests and done in a proper nano-secured facility. Using state of the art instrumentation, concentration and size levels of the emitted particles were quantified. There was no significant particle release during the handling operations (tests \#1 to \#6). There has been a presence of low concentration of micronic particles for the nano-coated part during tests \#2 and \#4. These results were also compared with the results obtained from a same part but uncoated. No considerable difference was observed between the two except for the test of surface scratching.
During the sanding test (\#9), it has been found that the total number concentration of the released particles has been dominated by the nanoparticles with a mean diameter size of $35 \mathrm{~nm}$. This conclusion agrees with the results of Koponen et al., 2009 and Göhler et al., 2010. This should be noted that because the aerosol was sampled directly in the vicinity of the particle generation source, the measured particle numbers represent maximum possible values in a practical case. The concept of wear energy has been introduced to the present study. It has proved to be a valuable indicator for forecasting the behavior of particles' emission. From the trend observed during experimental conditions, it may be suggested that with wear energy, particle emission increases. With the use of primary force-energy relationships, wear energy has been approximated and was found to be showing a positive correlation with particle emission. However, this hypothesis still needs more experimental trials to get verified.

Although the present study itself provides some of the valuable information on the particle emission behavior, it still demands both an improved energy model as well as refined experimental setup to understand the particleenergy interaction at microscale. The wear energy calculation must take into consideration that the frictional force is not a constant term. For the present study, there were limited number of test samples but authors will follow the work with more samples in order to provide a versatile asset to this study. As seen in the study, there has either been very weak release of the nanoparticles during handling operations or a strong release at higher energy levels. Therefore, in between these two extreme states, more sophisticated experimental procedures are 
Table 4. Wear energy and particle emission associated with tests \#6 to \#9.

\begin{tabular}{ccc}
\hline Test & Wear energy $(\mathrm{J})$ & $\begin{array}{c}\text { Total particle number } \\
\text { concentration }\left(\# / \mathrm{cm}^{3}\right)\end{array}$ \\
\hline Accidental fall & 0.2 & 10 \\
Scratching & 0.32 & 12 \\
Sawing & 0.48 & 300 \\
Sanding & 8 & 100,000 \\
\hline
\end{tabular}

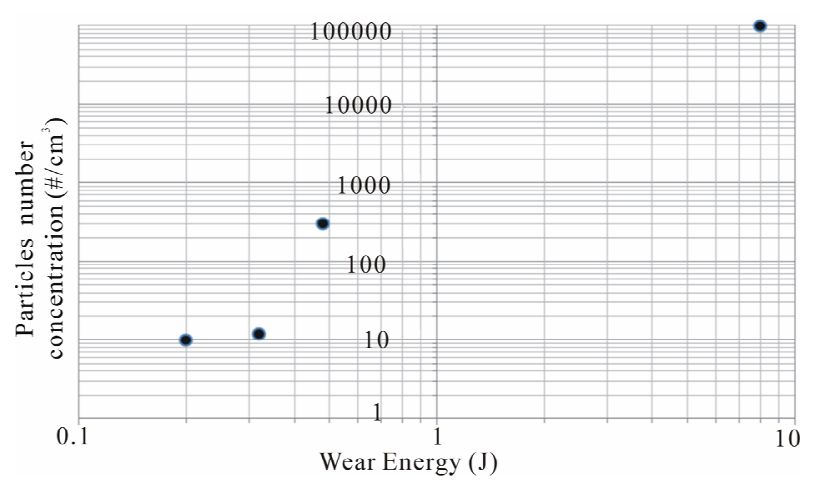

Figure 4. Total particle concentration versus dissipated energy.

required to set and measure the applied wear energy. To verify the emissions and their characteristics, the scanning electron microscopy and chemical analysis of the fullerenes are required which will be followed in the subsequent work.

\section{Acknowledgements}

The authors wish to thank the French Ministry of Ecology and the European project FOREMOST for the financial supports of this study.

\section{REFERENCES}

[1] AFSSET (2010) "Évaluation des Risques Liés aux Nanomatériaux Pour la Population Générale et Pour l'Environnement," Saisine No. 2008/005, Rapport d'Expertise Collective, 2010.

http://www.afsset.fr/upload/bibliotheque/4605522301014 68097041324565478/10_03_ED_Les_nanomateriaux_Ra pport_compresse.pdf

[2] L. Reijnders, "The Release of $\mathrm{TiO}_{2}$ and $\mathrm{SiO}_{2}$ Nanoparticles from Nanocomposites," Polymer Degradation and Stability, Vol. 94, No. 5, 2009, pp. 873-876. doi:10.1016/j.polymdegradstab.2009.02.005

[3] T. Nguyen, et al., "Fate of Nanoparticles during Life Cycle of Polymer Nanocomposites," Journal of Physics: Conference Series, Vol. 304, No. 1, 2010, Article ID: 012060.

[4] T. Schneider, D. H. Brouwer, I. K. Koponen, K. A. Jensen and W. Fransman, B. Van Duuren-Stuurman, M. Van
Tongeren and E. Tielemans, "Conceptual Model for Assessment of Inhalation Exposure to Manufactured Nanoparticles," Journal of Exposure Science and Environmental Epidemiology, Vol. 21, No. 5, 2011, pp. 450-463. doi:10.1038/jes.2011.4

[5] O. Le Bihan and K. Schierholz, "Assessment of Nanoparticles Emission from Manufactured Products: Feasibility Study," Proceedings of Nanosafe 2008: International Conference on Safe Production and Use of Nanomaterials, Grenoble, 3-7 November 2008.

[6] A. Zimmer and A. Maynard, "Investigation of the Aerosols Produced by a High-Speed, Hand-Held Grinder Using Various Substrates," Annals of Occupational Hygiene, Vol. 46, No. 8, 2002, pp. 663-672. doi:10.1093/annhyg/mef089

[7] I. K. Koponen, K. A. Jensen and T. Schneider, "Sanding Dust from Nanoparticle-Containing Paints," Journal of Physics: Conference Series, Vol. 151, No. 1, 2009, Article ID: 012048.

[8] L. Golanski, A. Guiot, D. Braganza and F. Tardif, "New Method for the Characterization of Abrasion Induced Nanoparticle Release into Air from Nanomaterials," Proceedings of Nanotechnology, 2010.

$\mathrm{http}: / /$ materiales.azc.uam.mx/area/Ingenieria Materiales/in vestigaci\%C3\%B3n/2261204/cuan\%20calif/Cuan\%20Tech ConWo2010/CD/Nanotech2010/pdf/905.pdf

[9] A. Guiot, L. Golanski and F. Tardif, "Measurement of Nanoparticle Removal by Abrasion," Journal of Physics: Conference Series, Vol. 170, No. 1, 2009, Article ID: 012014.

[10] M. Vorbau, L. Hilleman and M. Stintz, "Method for the Characterization of the Abrasion Induced Nanoparticle Release into Air from Surface Coatings," Aerosol Science, Vol. 40, No. 3, 2009, pp. 209-217.

[11] D. Göhler, M. Stintz, L. Hillemann and M. Vorbau, "Characterization of Nanoparticles Release from Surface Coatings by the Simulation of a Sanding Process," Annals of Occupational Hygiene, Vol. 54, No. 6, 2010, pp. 615624. doi:10.1093/annhyg/meq053

[12] L. G. Cena and T. M. Peters, "Characterization and Control of Airborne Particles Emitted during Production of Epoxy/Carbon Nanotube Nanocomposites," Occupational and Environmental Hygiene, Vol. 8, No. 2, 2011, pp. 8692. doi:10.1080/15459624.2011.545943

[13] S. Sachse, F. Silva, H. Zhu, A. Irfan, A. Leszczynska and K. Pielichowski, "The Effect of Nanoclay on Dust Generation during Drilling of PA6 Nanocomposites," Journal of Nanomaterials, 2012, Article ID: 189386. doi: $10.1155 / 2012 / 189386$

[14] J. C. Soo, P. J. Tsai, C. H. Chen, M. R. Chen, K. I. Hsu and T. N. Wu, "Influence of Compressive Strength and Applied Force in Concrete on Particles Exposure Concentrations during Cutting Processes," Science of the Total Environment, Vol. 409, No. 17, 2011, pp. 3124-3128. doi:10.1016/j.scitotenv.2011.05.016

[15] L. Y. Hsu and H. M. Chein, "Evaluation of Nanoparticles Emissionfor $\mathrm{TiO}_{2}$ Nanopowder Coating Materials," Nanoparticle Research, Vol. 9, No. 1, 2007, pp. 157-163. 